\title{
TRANSMISSÃO DE PREÇOS NA CADEIA DE CARNE SUÍNA: UMA APLICAÇÃO PARA OS PREÇOS DE SÃO PAULO ${ }^{1}$
}

\author{
Celso Leonardo Weydmann ${ }^{2}$ \\ Fernando Seabra
}

\begin{abstract}
Resumo - Transformações ocorridas na cadeia suína permitem que se questione se o segmento atacadista-processador de carne suína é líder na transmissão do preço e, também, se preços são indicadores eficientes. Para isso, procurou-se identificar a liderança de preços na cadeia e os efeitos da instabilidade dos preços sobre três níveis de preços da cadeia suinícola de São Paulo no período de 1995 a 2005. Por meio de um modelo VAR, incluindo a instabilidade de preços (processo ARCH), e do teste de causalidade de Granger, constatou-se que os preços do atacado são transmitidos ao setor produtor e que a variância condicional dos preços do atacado é transmitida aos preços do produtor e varejo. Concluiu-se que a cadeia suinícola segue o mesmo padrão de liderança de outras cadeias e que a ineficiência nela fragiliza especialmente o setor produtor.
\end{abstract}

Palavras-chave: transmissão de preço, cadeia produtiva, carne suína.

\section{Introdução}

Conforme ocorre com outras cadeias de carnes, a cadeia suinícola passa por diversas mudanças, como o avanço tecnológico na produção de insumos e de animais (Santini e Souza Filho, 2004), as alterações na geografia da produção - expandindo-se os rebanhos em direção à região Centro-Oeste - e os ganhos da competitividade da indústria de abate e processamento de carne suína, tendo em vista as crescentes exportações

\footnotetext{
Os autores agradecem os comentários do Prof. João Sanson e de dois pareceristas anônimos, isentando-os, todavia, de qualquer erro remanescente.

2 Professor Titular do Departamento de Economia da Universidade Federal de Santa Catarina. E-mail: celsolw@cse.ufsc.br

3 Professor Titular do Departamento de Economia da Universidade Federal de Santa Catarina. E-mail: seabra@cse.ufsc.br
} 
do setor (Silva Júnior et al., 2003). Essas transformações podem ser vistas como alternativas para o setor superar algumas restrições, como o baixo consumo interno (Deschamps et al.,1998), a concorrência de outras carnes - a bovina e, principalmente, de frango (Santana, 1999) - e o crescimento das redes de supermercados, tendo estes maior poder de ditar preços (Blecher, 2002).

Os ganhos de eficiência na produção e a maior concorrência no atacado e varejo são compatibilizados por ajustes de preços dos agentes na cadeia. Para evitar o achatamento das margens, cada agente procura repassar as variações desfavoráveis dos preços. Estudos realizados nos anos $80 \mathrm{e}$ 90 mostram que a liderança na transmissão dos preços está no segmento de industrialização, quando o produto é processável, e no atacado, para perecíveis (Aguiar, 1993). No caso da carne de frango, Bittencourt e Barros (1996) constataram a importância do setor processador na formação dos preços na região Sul. Conforme apontado por Paula (2000), a liderança do segmento processador pode ser contraposta pela ampliação do poder de mercado do setor varejista, ou seja, as transformações e restrições descritas anteriormente podem ter também atingido a liderança na formação de preços dentro da cadeia suinícola. Daí, questiona-se: o segmento processador de carne suína é líder na transmissão do preço na cadeia? Dado o acirramento da concorrência, a variabilidade do preço de um segmento tem impacto nos preços de outros segmentos, ou seja, os preços na cadeia não são indicadores eficientes?

Assim, neste trabalho, analisaram-se os preços da carne suína em nível do produtor, atacado e varejo em São Paulo, com os objetivos de identificar a liderança na transmissão dos preços e, ainda, verificar a influência da variabilidade dos preços de cada segmento sobre os preços dos demais segmentos.

Supõe-se que o segmento atacadista de carne suína é o líder na transmissão de preços na cadeia. Admite-se também que a variabilidade dos preços no setor atacadista influencia a transmissão dos preços dos demais setores. Nesse sentido, a cadeia suinícola teria mantido nos últimos anos o padrão de liderança já estabelecido em outras cadeias, porém a 
formação de preços na cadeia teria perdido eficiência porque haveria transmissão da variabilidade dos preços entre os segmentos.

A importância do trabalho reside na tentativa de reduzir a lacuna da falta de análise de preços na cadeia de carne suína, a qual também pode auxiliar na melhor compreensão da crise de preços vivenciada pelo segmento produtor.

\section{Revisão de literatura}

Nesta seção apresentam-se evidências da literatura para dar suporte às hipóteses do estudo, formuladas na seção anterior.

A transmissão de preços trata da identificação do agente da cadeia (produtor, atacadista e varejista) que origina a mudança de preços da carne suína, ao qual se denomina líder. Segundo Barros (1990), a liderança está associada à sensibilidade do setor às variações da oferta e demanda, ao custo para alterar os preços, à quantidade de transações com poucos produtos (especialização) e ao risco de prejuízo importante caso as transações não se concretizem. O segmento produtor, por ser atomizado, não teria poder de fixar preços e o setor varejista é não- especializado e faria ajustes graduais nos preços, visando preservar uma margem de ganho considerada adequada. Esta última visão, entretanto, não é compartilhada por Becker (1999), para quem o setor varejista evitaria freqüentes remarcações de preços, fazendo-as apenas sob pressão significativa dos custos. De qualquer maneira, portanto, parece que choques de oferta e demanda inicialmente influenciariam os preços do setor atacadista ${ }^{4}$.

Segundo Aguiar (1993), a variação do preço iniciada no atacado é ajustada por meio de defasagem distribuída no tempo pelos produtores e varejistas. Bittencourt e Barros (1996) constataram um período de três meses para

4 Aguiar (1993) resume outros modelos que relacionam preços nos diversos segmentos de comercialização, formulados nos anos 70 e 80 . 
que o preço do frango retornasse ao estado de equilíbrio e concluíram pela eficiência dos preços dos produtores de frango dos estados de Santa Catarina, Paraná e São Paulo, justificado pelo alto grau de integração da avicultura destes estados. Para Jones (2005), a eficiência do mercado ocorre quando toda a informação disponível no mercado no tempo $t$ é refletida nos preços contemporâneos. No entanto, se a volatilidade dos preços é transmitida entre os segmentos do mercado, então é possível que a informação de um segmento seja utilizada para prever os preços em outro segmento, contrariando a hipótese de mercado eficiente. Este autor concluiu pela existência de ineficiência na cadeia de carne suína americana ao constatar forte transmissão das variações dos preços dos segmentos produtor e atacado. Portanto, havendo ineficiência do mercado, o tempo de ajuste dos preços para retornar ao equilíbrio pode ser maior em relação ao mercado, caso seja eficiente.

Outro aspecto destacado por Aguiar (1993) é a intensidade da transmissão dos preços, que tende a ser maior nos primeiros meses após o choque inicial. A intensidade é medida pela elasticidade de transmissão de preços e tende a ser igual ou menor que um, implicando que os agentes de comercialização não amplificam os choques de preços. As elasticidades de transmissão de preços entre atacado e produtor não são muito diferentes das elasticidades entre atacado e varejo. $\mathrm{O}$ autor destaca que elasticidades maiores que um foram obtidas entre os mercados externo e interno para o preço da soja.

A transmissão de preços também pode ser assimétrica entre os níveis de mercado. Hahn (1990 apud Aguiar, 1993) detectou que, no caso de produtos de carne suína e bovina, o varejo transmite mais intensamente as elevações de preço, dada a variação deste no atacado. A explicação estaria na estrutura concentrada do setor e na inelasticidade da demanda. Nesse sentido, Santana (1999) estimou que a elasticidade-preço da carne de frango é - 0,332; de boi, - 0,271 (demandas inelásticas); e zero (demanda perfeitamente inelástica) para carne suína.

Bacchi (1995) verificou a transmissão de preços recebidos pelos produtores de bovino, suíno e frango em São Paulo por meio do modelo 
de causalidade de Sims. Os resultados indicaram que o preço do frango é transmitido ao preço do suíno e bovino, o que refletiria a queda do preço da carne de frango e sua crescente importância no consumo. Em períodos de queda do preço da carne suína, o preço da carne de frango também cai. Santana (1999) obteve evidências de elasticidade cruzada da demanda entre as carnes, sendo a carne de frango substituta complementar da suína e bovina, pelo fato de ser consumida com as outras carnes. Já a carne suína revelou-se substituta das outras.

As evidências mostram que pouco se sabe sobre a transmissão de preço na cadeia da carne suína. Assim, e por semelhança com a transmissão que ocorre em outras cadeias, argumenta-se que o setor atacadista é o líder na transmissão de preços na cadeia suína, por reunir as características apontadas na revisão. Tendo em vista a grande expansão do consumo de carne de frango e a complementariedade do seu consumo com a carne suína, então esta última possui a demanda mais elástica aos preços, os quais tendem apresentar maior variabilidade. Como a demanda tende a ser estável e o segmento produtor é atomizado, então a variabilidade dos preços do atacado contamina os preços do varejo e do produtor, seguindo o padrão da liderança de transmissão dos preços. Em decorrência, a cadeia suína não seria eficiente e o tempo de ajuste tenderia a ser maior entre os agentes diante das variações de preço. Essas afirmações serão verificadas nas próximas seções.

\section{A cadeia de carne suína brasileira}

O Brasil detém a quarta posição no ranking mundial tanto em termos de produção de carne suína quanto em relação às exportações desse produto, tendo alcançado em 2005 uma produção de 2.732 mil toneladas e uma exportação de 625 mil toneladas. No período 2000 a 2005, as exportações cresceram $362 \%$ e a produção interna evoluiu apenas $6,8 \%$, refletindo uma queda no consumo interno de $14 \%$, que totalizou 2.084 mil toneladas. A redução, segundo Deschamps et al. (1998), está associada com o alto preço, a maior proporção de itens industrializados $(70 \%)$ em relação à 
carne in natura e os preconceitos contra a carne suína, como pouco saudável e excessivamente gorda. De acordo com a ABIPECS (2005), outros fatores também contribuem para isso, como a concorrência da carne de frango e boi e o consumo de carnes mais baratas. Portanto, o crescimento das vendas externas tem compatibilizado a demanda e oferta domésticas, evitando uma tendência de queda mais expressiva dos preços na última década, conforme pode ser visto no Gráfico 1.

A região Sul possui mais da metade do rebanho nacional, seguida pela regiões Sudeste e Centro-Oeste; nesta última verificam-se as maiores taxas de expansão do rebanho nos últimos anos. No Sul, a produção suinícola é organizada majoritariamente na forma de integração entre produtoras e agroindústrias e tem os melhores índices tecnológicos, como a média de dias não-produtivos das fêmeas, o número de leitões desmamados por fêmea, a idade de desmame e a taxa de conversão alimentar. O preço é baseado em um preço-base, definido por cooperativas e agroindústrias, adicionado de um percentual que varia de acordo com os índices zootécnicos. A região é a grande abastecedora dos mercados paulista, carioca, mineiro, baiano e cearense (Santos e Aguiar, 2003).

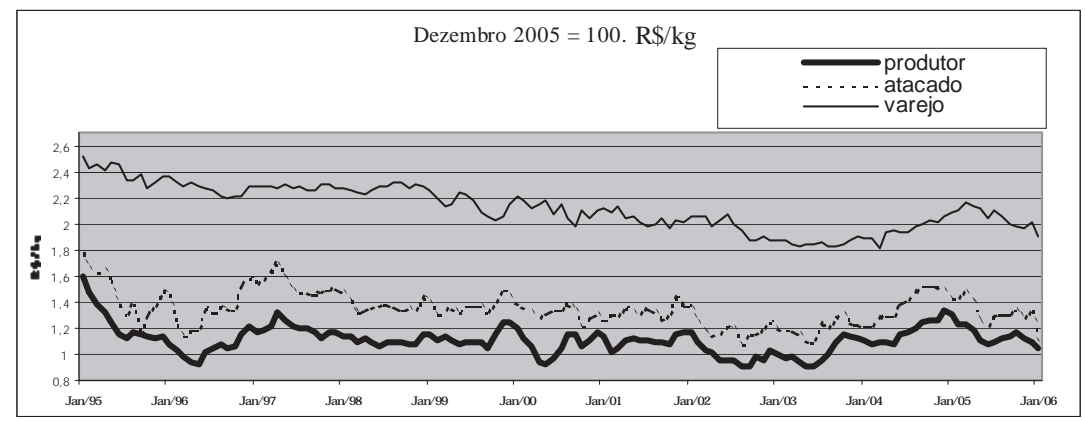

Gráfico 1 - Preços da carne suína em São Paulo - 1995 - 2006. Fonte: Instituto de Economia Agrícola - SP. 
Fora do Sul predominam os produtores independentes. Para Pinheiro (2000 apud Santos e Aguiar, 2003), a determinação do preço é baseada no mercado percebido pelos produtores e compradores em reuniões semanais, o que minimizaria os riscos de grandes oscilações de preços. O preço tende a ser $40 \%$ maior que no Sul em determinadas épocas do ano, enquanto a volatilidade é maior em São Paulo e na região Sudeste (comparativamente ao Sul), evidenciando que os suinocultores sulistas estão mais expostos ao risco de preço.

A estrutura do setor atacadista, composto pelas agroindústrias e frigoríficos, caracteriza-se pela concentração geográfica e do número de empresas. Em 2004, cerca de $88 \%$ do abate sob inspeção federal, totalizando cerca de 24,3 milhões de cabeças, foi nos três estados da região Sul, em São Paulo e Minas Gerais; as seis maiores empresas processadoras abateram a metade daquele total (ABIPECS, 2004). A tendência do segmento é de crescente concentração (Santos e Aguiar, 2003).

O setor varejista se caracteriza pela concentração. Em 1997, as cinco maiores redes varejistas atendiam $27 \%$ do mercado, chegando a $39 \%$ em 2002. Com isso, as grandes redes têm elevado seu poder de negociação com os fornecedores, o que, segundo elas, tem favorecido a estabilidade dos preços no varejo. Alternativamente, existem as redes médias, os pequenos varejos e os supermercados de vizinhança localizados no subúrbio e na periferia das grandes cidades (Blecher, 2003). Segundo Neves e Machado Filho (1996), essas tendências também foram percebidas no varejo europeu, constituindo-se os hipermercados e supermercados nos locais de maior expansão na compra de carnes e frios.

Em resumo, a cadeia suinícola possui uma estrutura atomizada na produção, sendo a organização da produção e a formação de preços distintas na região Sul e no resto do país. O setor de abate é concentrado em poucas grandes empresas, que produzem embutidos com maior preço do que as carnes de frango e bovina, o que explica o baixo consumo de 
carne suína. As crescentes vendas de carne suína ao mercado externo, por sua vez, atribuem maior poder de negociação ao mercado atacadista, uma vez que ocorre a expansão da demanda. Por fim, a concentração das redes de supermercados - e a intensa concorrência via preços entre eles - implica dificuldades de o varejo repercutir aumentos de preços no atacado.

\section{Metodologia}

A análise dos preços da cadeia suína utiliza os preços do produtor, atacado e varejo disponibilizados no sítio do Instituto de Economia Agrícola de São Paulo para o período de janeiro de 1995 a janeiro de $2006^{5}$. Os dados foram deflacionados para dezembro de 2005, usando-se o IPAOG - carnes e derivados da FGV.

A análise econométrica consiste em um modelo vetor auto-regressivo estimado em dois estágios. Sob a hipótese de que a instabilidade dos preços, nos três mercados considerados, também influencia a transmissão entre os preços do produtor, atacado e varejo, estima-se, primeiramente, um modelo $\mathrm{ARCH}^{6}$ para computar a variabilidade condicionada dos preços. A vantagem da estimação por este método é que se mede a variância condicional - e não incondicional, como em estudos anteriores, a exemplo de Jones (1995) - do preço do produto. O segundo estágio diz respeito à estimação do VAR propriamente dito. Neste modelo, os preços de carne suína nos três mercados, produtor, atacado e varejo, são tratados como endógenos e as variâncias condicionais (obtidas no primeiro estágio) como exógenas. Em termos matemáticos, o modelo VAR está descrito pelas equações (1)-(3), e as equações para estimação da variância condicional (modelo ARCH), pelas equações (4)-(6), como segue:

\footnotetext{
http://www.iea.sp.gov.br/

$6 \mathrm{O}$ modelo ARCH (heteroscedasticidade condicional auto-regressiva) foi originalmente desenvolvido por Engle (1982).
} 


$$
\begin{aligned}
& \mathrm{pp}_{\mathrm{t}}=\mathrm{a}_{0}+\sum_{\mathrm{i}=1}^{\mathrm{q}} \mathrm{a}_{1 \mathrm{i}} \mathrm{pp} \mathrm{p}_{\mathrm{t}-\mathrm{i}}+\sum_{\mathrm{j}=1}^{\mathrm{q}} \mathrm{a}_{2 \mathrm{j}} \mathrm{pa}_{\mathrm{t}-\mathrm{j}}+\sum_{\mathrm{m}=1}^{\mathrm{q}} \mathrm{a}_{3 \mathrm{~m}} \mathrm{pv}_{\mathrm{t}-\mathrm{m}}+\mathrm{a}_{4} \mathrm{~h}_{\mathrm{pp}}+\mathrm{a}_{5} \mathrm{~h}_{\mathrm{pa}}+\mathrm{a}_{6} \mathrm{~h}_{\mathrm{pv}}+\mathrm{e}_{1} \\
& \mathrm{pa}_{\mathrm{t}}=\mathrm{b}_{0}+\sum_{\mathrm{i}=1}^{\mathrm{q}} \mathrm{b}_{\mathrm{li}} \mathrm{pp}_{\mathrm{t}-\mathrm{i}}+\sum_{\mathrm{j}=1}^{\mathrm{q}} \mathrm{b}_{2 \mathrm{j}} \mathrm{pa}_{\mathrm{t}-\mathrm{j}}+\sum_{\mathrm{m}=1}^{\mathrm{q}} \mathrm{b}_{3 \mathrm{~m}} \mathrm{pv}_{\mathrm{t}-\mathrm{m}}+\mathrm{b}_{4} \mathrm{~h}_{\mathrm{pp}}+\mathrm{b}_{5} \mathrm{~h}_{\mathrm{pa}}+\mathrm{b}_{6} \mathrm{~h}_{\mathrm{pv}}+\mathrm{e}_{2} \\
& \mathrm{pv}_{\mathrm{t}}=\mathrm{c}_{0}+\sum_{\mathrm{i}=1}^{\mathrm{q}} \mathrm{c}_{1 \mathrm{i}} \mathrm{pp}_{\mathrm{t}-\mathrm{i}}+\sum_{\mathrm{j}=1}^{\mathrm{q}} \mathrm{c}_{2 \mathrm{j}} \mathrm{pa}_{\mathrm{t}-\mathrm{j}}+\sum_{\mathrm{m}=1}^{\mathrm{q}} \mathrm{c}_{3 \mathrm{~m}} \mathrm{pv}_{\mathrm{t}-\mathrm{m}}+\mathrm{c}_{4} \mathrm{~h}_{\mathrm{pp}}+\mathrm{c}_{5} \mathrm{~h}_{\mathrm{pa}}+\mathrm{c}_{6} \mathrm{~h}_{\mathrm{pv}}+\mathrm{e}_{3} \\
& h_{p p, t}=\sum_{i=0}^{p} d_{i} \hat{u}_{p p, t-i-1}^{2} \quad \text { dado } \quad p p_{t}=\sum_{j=1}^{m} f_{j} p p_{t-j}+u_{p p, t} \\
& h_{p a, t}=\sum_{i=0}^{p} d_{i} \hat{u}_{p a, t-i-1}^{2} \quad \text { dado } \quad p a_{t}=\sum_{j=1}^{m} f_{j} p a_{t-j}+u_{p a, t} \\
& h_{p v, t}=\sum_{i=0}^{p} d_{i} \hat{u}_{p v, t-i-1}^{2} \quad \text { dado } \quad p v_{t}=\sum_{j=1}^{m} f_{j} p v_{t-j}+u_{p v, t}
\end{aligned}
$$

em que $p p$ : preço da carne suína pago ao produtor; pa: preço da carne suína pago no atacado; $p v$ : preço da carne suína pago no varejo; $h_{p p}, h_{p a}, h_{p v}$ : variâncias condicionais dos preços em cada um dos mercados; $e_{1}, e_{2}, e_{3}$ : termos estocásticos em cada uma das equações de transmissão de preços; e $u_{p p}, u_{p a}, u_{p v}$ : erros da equação da média no modelo ARCH, os quais são usados para estimação da variância condicional de cada mercado. As defasagens no modelo $\operatorname{VAR}(q)$ e no modelo ARCH ( $p$ e $m$ ) são determinadas pelo critério de Akaike.

Por fim, no sentido de ratificar a direção dos mecanismos de transmissão, procede-se ao teste de causalidade de Granger, estimado a partir da própria estrutura do modelo VAR. Este teste tem sido utilizado para aferir o sentido dos preços entre mercados ${ }^{7}$. Conforme alertado por Enders (2003), a causalidade de Granger mede unicamente os efeitos dos valores

\footnotetext{
${ }^{7}$ Um exemplo de aplicações do teste de causalidade de Granger para mercados agrícolas de diversos países é Conforti (2004).
} 
passados, por exemplo, de $\mathrm{X}_{\mathrm{t}}$ nos valores contemporâneos de $\mathrm{Y}_{\mathrm{t} . ;}$ ou seja, o teste não trata da causalidade contemporânea entre $\mathrm{X}_{\mathrm{t}} \mathrm{e} \mathrm{Y}_{\mathrm{t}}^{\mathrm{8}}$.

\section{Análise dos resultados}

De modo preliminar à estimação do modelo VAR, as séries de preços foram submetidas ao teste ADF para detectar a presença de raízes unitárias. Como pode ser visto na Tabela A1 do Anexo, os testes mostraram que as três variáveis são estacionárias a 5\%. Além disso, as Tabelas A2, A3 e A4, também no Anexo, mostram a decomposição da variância do preço da carne suína nos três segmentos de comercialização. Na Tabela A2, na qual se tem a decomposição da variância do preço do produtor, nota-se que os preços do atacado explicam uma parcela grande do erro de previsão nos dois primeiros meses. Por meio da Tabela A3, pode-se verificar que a variância do preço da carne suína no atacado não é explicada pelos demais preços, o que pode indicar a condição de segmento formador de preço no mercado. A variância do preço da carne suína no varejo (Tabela A4) inicialmente não é explicada pelos outros preços, porém nota-se que é crescente a influência dos preços do atacado com o passar do tempo. Esses resultados sugerem que os preços do atacado exercem influência importante na formação dos preços do produtor e do varejo.

Para examinar de modo mais detalhado a hipótese de transmissão de preços entre os três mercados, estima-se um modelo VAR de acordo

\footnotetext{
8 O teste pode ser visto como composto de duas regressões para todos os pares de variáveis na análise.

$\mathrm{y}_{\mathrm{t}}=\alpha_{0}+\alpha_{1} \mathrm{y}_{\mathrm{t}-1}+\ldots+\alpha_{\mathrm{n}} \mathrm{y}_{\mathrm{t}-1}+\beta_{1} \mathrm{x}_{\mathrm{t}-1}+\ldots+\beta_{\mathrm{n}} \mathrm{x}_{\mathrm{t}-\mathrm{n}}+\varepsilon_{\mathrm{t}}$

$\mathrm{x}_{\mathrm{t}}=\alpha_{0}+\alpha_{1} \mathrm{x}_{\mathrm{t}-1}+\ldots+\alpha_{\mathrm{n}} \mathrm{x}_{\mathrm{t}-\mathrm{n}}+\beta_{1} \mathrm{y}_{\mathrm{t}-1}+\ldots+\beta_{\mathrm{n}} \mathrm{y}_{\mathrm{t}-\mathrm{n}}+{ }_{\mathrm{t}} \quad$ (2)

Na primeira regressão verifica-se a influência dos valores passados de $\mathrm{x}$ (até a defasagem $\mathrm{t}-\mathrm{n}$ ) nos valores contemporâneos de y, sendo esta influência invertida na segunda regressão. O resultado do teste é baseado na estatística $\mathrm{F}$ com base no teste de Wald em cada regressão para verificar a seguinte hipótese:

$\mathrm{H}_{0}: \beta_{1}=\beta_{2}=\ldots=\beta_{\mathrm{n}}=0$

A hipótese nula é que x não causa y, no sentido de Granger, na regressão (1), e que y não causa x, no sentido de Granger, na regressão (2).

O resultado pode indicar causação unidirecional quando apenas os coeficientes de uma das variáveis defasadas são significantes, indicando que $\mathrm{X}$ causa $\mathrm{Y}$ ou $\mathrm{Y}$ causa $\mathrm{X}$. Pode haver causação bidirecional quando os valores defasados de ambas as variáveis são significantes - neste caso, $\mathrm{Y}$ causa X e X causa $\mathrm{Y}$.
} 
com as equações (1), (2) e (3). O primeiro passo é a estimação da variância condicional a partir da formulação de um modelo auto-regressivo para o preço de cada mercado. O teste ARCH foi estatisticamente significativo para os três casos, e as variâncias condicionais $\left(h_{p p}, h_{p a}\right.$, $h_{p v}$ ) foram então estimadas com base nas variâncias passadas e com o número de defasagens escolhido pelo critério de Akaike. Os resultados dos testes ARCH estão na Tabela A5, no Anexo. O segundo passo é a estimação do modelo VAR propriamente dito, cujos resultados estão na Tabela 1 .

É importante notar que os coeficientes dos preços são elasticidades, uma vez que essas séries foram transformadas em logaritmos. O preço da carne suína ao produtor é o que sofre mais influência dos preços nos demais mercados, o que evidencia a fragilidade deste segmento da cadeia produtiva (em relação ao atacado e varejo). Isso é ainda confirmado pelo fato de o preço ao produtor defasado não ser significativo na determinação do preço da carne suína nos mercados de atacado e varejo. De fato, o preço no atacado é influenciado pelos próprios preços passados e pelo preço no varejo defasado um mês (e com uma elasticidade positiva igual a 0,283 ). De modo muito semelhante, os preços do varejo são também influenciados pelos próprios preços em meses anteriores e pelo preço do atacado defasado (com elasticidade de 0,266 ). Os resultados do modelo VAR indicam que as equações para os preços ao produtor e para o varejo são mais bem especificadas, o que corrobora o resultado de que os preços no atacado são menos dependentes dos preços nos demais mercados.

Quanto aos efeitos da variância condicional dos preços, os resultados indicam que apenas a instabilidade dos preços no atacado é estatisticamente significativa nas equações dos preços ao produtor e do próprio preço ao atacado. Esse resultado confirma o papel decisivo do mercado de atacado não só quanto ao nível de seus preços, mas também quanto à variabilidade destes. 
Uma vez detectada alguma influência entre os preços dos segmentos, utilizou-se o modelo de causação de Granger para melhor determinar o sentido de influência dos preços, conforme a Tabela A6, no Anexo. Os preços do atacado e varejo Granger-causam os preços do produtor, significando que os preços contemporâneos deste último sofrem influência significante dos preços passados do atacado e varejo. Os resultados também indicam que os preços do varejo e do produtor não Grangercausam os preços do atacado e que os preços do atacado Grangercausam os preços do varejo. Em resumo, os resultados corroboram a maior exogeneidade dos preços do atacado em relação aos preços ao produtor e varejo, situando, portanto, neste mercado o principal foco de origem de transmissão de preços para a cadeia de carne suína. 
Tabela 1 - Estimativas do modelo VAR para os preços do suíno ao produtor e da carne suína no atacado e no varejo. São Paulo. 1995-2006

\begin{tabular}{lccc}
\hline Coeficientes & \multicolumn{3}{c}{ Variável Dependente } \\
\cline { 2 - 4 } Constante & $\mathrm{PP}_{\mathrm{t}}$ & $\mathrm{PA}_{\mathrm{t}}$ & $\mathrm{PV}_{\mathrm{t}}$ \\
& $0,156^{*}$ & $0,204^{*}$ & 0,045 \\
$\mathrm{PP}_{\mathrm{t}-1}$ & $(2,45)$ & $(2,05)$ & $(0,63)$ \\
& $0,570^{*}$ & $-0,327$ & $-0,055$ \\
$\mathrm{PP}_{\mathrm{t}-2}$ & $(4,29)$ & $(-1,59)$ & $(-0,37)$ \\
& 0,107 & 0,094 & 0,004 \\
$\mathrm{PA}_{\mathrm{t}-1}$ & $(0,89)$ & $(0,50)$ & $(0,037)$ \\
& $0,466^{*}$ & $1,243^{*}$ & $0,266^{*}$ \\
$\mathrm{PA}_{\mathrm{t}-2}$ & $(5,13)$ & $(8,80)$ & $(2,61)$ \\
& $-0,295^{*}$ & $-0,276^{*}$ & $-0,116$ \\
$\mathrm{PV}_{\mathrm{t}-1}$ & $(-3,16)$ & $(-1,91)$ & $(-1,11)$ \\
& $0,206^{*}$ & $0,283^{*}$ & $0,682^{*}$ \\
$\mathrm{PV}_{\mathrm{t}-2}$ & $(2,50)$ & $(2,20)$ & $(7,34)$ \\
& $-0,22^{*}$ & $-0,242^{*}$ & $0,226^{*}$ \\
$\mathrm{~h}_{\mathrm{pp}, \mathrm{t}}$ & $(-2,93)$ & $(-2,00)$ & $(2,58)$ \\
& $-2,599$ & 3,655 & $-2,213$ \\
$\mathrm{~h}_{\mathrm{pa}, \mathrm{t}}$ & $(-0,55)$ & $(0,49)$ & $(-0,41)$ \\
& $6,137^{*}$ & $5,774^{*}$ & 1,746 \\
$\mathrm{~h}_{\mathrm{pv}, \mathrm{t}}$ & $(3,40)$ & $(2,06)$ & $(0,86)$ \\
$\mathrm{R}^{2}$-ajustado & $-4,673$ & $-9,579$ & $-4,927$ \\
Akaike (AIC) & $(-0,90)$ & $(-1,19)$ & $(-0,84)$ \\
\hline
\end{tabular}

* significante a 5\%; PP — preço do produtor; PA — preço do atacado; PV preço do varejo; hpp - variância do preço do produtor; hpa - variância do preço do atacado; hpv - variância do preço do varejo.

Fonte: Dados da pesquisa.

\section{Conclusões}

A análise da decomposição da variância permitiu verificar que os preços do atacado explicam parte importante dos erros de previsão do produtor. O modelo VAR mostrou que os preços da carne suína ao produtor são significativamente influenciados por variações passadas dos preços do 
atacado e varejo. Os preços do varejo são também afetados de modo significativo por variações defasadas de preços no nível de atacado. Além disso, os preços do atacado Granger-causam os preços do produtor e varejo. Em decorrência desses resultados, pode-se afirmar que há fortes evidências para aceitar a hipótese de que os preços do atacado lideram a transmissão do preço ao setor produtor e também ao setor varejista. Dessa forma, este estudo corrobora a importância do atacado na transmissão do preço já constatada por Aguiar (1993), Bacchi (1995) e Bittencourt e Barros (1996).

Outro resultado encontrado é que a variabilidade dos preços do atacado (medida pela variância condicional da série) é transmitida aos preços do produtor e varejo, o que aponta para a existência de ineficiência na cadeia suína. Isso pode implicar que os preços na cadeia tendem a demorar mais tempo para retornar ao equilíbrio após um choque no preço do atacado. Essa instabilidade tem efeitos adversos mais importantes sobre o produtor de suínos, que - pela estrutura de produção existente - dispõe de menos recursos para se proteger do risco-preço. A inexistência de um mercado futuro para o preço do suíno pode explicar, pelo menos parcialmente, a maior vulnerabilidade do produtor em relação a variações sazonais e de choques de mercado, conforme já indicado por Jones (2005).

Estudos sobre a relação dos preços da cadeia da carne suína com preços de outras cadeias de carnes substitutas, como de frango e bovina, são extensões naturais do presente estudo e podem ampliar o entendimento da formação dos preços nesses mercados e a influência entre eles. 


\section{Referências}

AGUIAR, D.R.D. A Questão da transmissão de preços agrícolas. Revista de Economia e Sociologia Rural, v.31, n.4, p.291-308, out/ dez.1993.

Associação Brasileira das Indústrias Produtoras e Exportadoras de Carne Suína, ABIPECS. Relatório Anual, 2005.

Associação Brasileira das Indústrias Produtoras e Exportadoras de Carne Suína, ABIPECS. Relatório Anual, 2004.

BACCHI, M.R.P. Causalidade entre preços no mercado de carnes do estado de São Paulo. Revista de Economia e Sociologia Rural, SOBER, Brasília, v.34, n.2, p51-50, nov/dez/1995.

BARROS, G.S.A.C. Transmissão de preços pela central de abastecimento de São Paulo. Revista Brasileira de Economia, Rio de Janeiro, FGV, v.44, n.1, p. 5-20, jan./mar. 1990.

BECKER, G.S. Hog prices: questions and answers. The National Council for Science and the Environment. Washington, D.C. 1999. Disponível em: http;/www.agriculturelaw.com/aglibrary/articles/ hogprices_dec15_1999. Acesso em: 23/04/2002.

BITTENCOURT, M.V.L \& BARROS, G.S.C. Relações de preço de frango nas regiões Sul e Sudeste do Brasil. Revista de Economia e Sociologia Rural, v.34, n.3 e 4, p.147-169, jul/dez 1996.

BLECHER, N. A ditadura do varejo. Revista Exame, São Paulo, ano 36, n.12, junho 2002; pp.

CONFORTI, P. Price Transmission in Selected Agricultural Markets. In: Fao Commodity and Trade Policy Research Working Paper, no. 7, Mar. 2004. 
DESCHAMPS, J.C.; LUCIA JUNIOR, T.e TALAMINI, D.J.D. A cadeia produtiva da suinocultura. In: Agronegócio brasileiro, ciência, tecnologia e competitividade. Editado por Ruy de Araújo Caldas et al. Brasília, CNPq, 1998.

ENDERS, W. Applied econometric time series. John Wiley \& Sons, Inc. 2004.

ENGLE, R. Autoregressive Conditional Heteroskedasticity with Estimates of the Variance of UK Inflation. Econometrica, v. 50, p. 987-1008, 1982.

HAHN, W.F. Price transmission asymmetry in pork and beef markets. The Journal of Agricultural Economics Research, v. 42, n. 2, p. 21 30, 1990.

JONES, K.G. Price volatility and transmission in the hog and pork markets. Paper presented at the annual meeting of the Southern Agricultural Economics Association, Little Rock, Arkensas, 2005. Disponível em: $<$ http://agecon.lib.umn.edu/>. Acesso em: 04/2006.

NEVES, M.F. \& MACHADO FILHO. A distribuição varejista na Europa. In: Agribusiness Europeu. Cláudio A. Pinheiro Machado Filho, Eduaro Eugênio Spers, Fabio Ribas Chaddad e Marcos Fava Neves. São Paulo: Pioneira, 1996.

PAULA, N.M. Mudança estrutural na indústria alimentar: um survey sobre tendências à concentração. Revista de Economia e Sociologia Rural, Brasília, SOBER, v.38, n.3, 2003.

PINHEIRO, L.L. Condicionantes da competitividade da suinocultura na Zona da Mata Mineira. Viçosa: UFV, 2000.115p. Dissertação (Mestrado em Economia Rural) - Universidade Federal de Viçosa. 
SANTANA, A. C. Mudanças recentes nas relações de demanda de carne no Brasil. Revista Economia e Sociologia Rural, v.37, n.2, abr/ jun, 1999.

SANTINI, G. A.; SOUZA FILHO, H. M. . Mudanças tecnológicas em cadeias agroindustriais: uma análise dos elos de processamento da pecuária de corte, avicultura de corte e suinocultura. In: XLII Congresso Brasileiro de Economia e Sociologia Rural, 2004, Cuiabá. Congresso Brasileiro de Economia e Sociologia Rural, 2004. vol. 1.

SANTOS, A.H.G.; AGUIAR, D. Análise dos fatores determinantes da viabilidade de implantação do contrato futuro de suínos no Brasil. Revista de Economia e Agronegócio, Departamento de Economia Rural vol.1, 2, 2003 - Viçosa: UFV 2003-

SILVA JÚNIOR, A.G.; GOMES, M.F.M.; BARBOSA, T.R.C. e GALVÃO DA SILVA JÚNIOR, A. Programas de qualidade e indicadores de desempenho da indústria de abate e processamento de suínos na região Centro Sul do Brasil. Revista de Economia e Agronegócio, Departamento de Economia Rural, vol.1, no. 3, 2003. - Viçosa: UFV 2003-

Abstract - Changes in the pork chain bring about the discussion whether the wholesale sector has the leadership of price transmission and also if prices are efficient market indicators. The paper aims to identify what segment is the price leader in the pork chain and also to characterize the price volatility considering producer, wholesale and retail prices for the state of São Paulo between 1995 and 2005. The data analysis was conducted by estimating a VAR model which included an $\mathrm{ARCH}$ process for measuring price volatility. A Granger causality test was also implemented to check the price direction transmission. The results pointed out that price transmission occurs from wholesale to producer sectors and also that the price conditional variance for the wholesale sector is transmitted to producer and retail prices.

Key words: price transmission; pork chain, volatility. 


\section{Anexo}

Tabela A1 - Testes de raiz unitária para os preços (ADF)

\begin{tabular}{lclc}
\hline Variáveis & Defasagens(Akaike) & Modelo & Estatística t \\
\hline Preço produtor & 1 & Com constante & $-4,57^{*}$ \\
Preço atacado & 12 & Com constante e tendência & $-3,86^{* *}$ \\
Preço varejo & 0 & Com constante e tendência & $-4,02^{*}$ \\
\hline
\end{tabular}

$*$ significante a $1 \% ; * *$ significante a $5 \%$.

Fonte: Dados da pesquisa.

Tabela A2 - Decomposição da variância dos erros de previsão do preço do suíno ao produtor. São Paulo, 1995-2006. \%

\begin{tabular}{ccccc}
\hline Meses & Desvio-padrão & PP & PA & PV \\
\hline 1 & 0,03 & 44,67 & 55,32 & 0,00 \\
2 & 0,05 & 22,43 & 75,53 & 2,03 \\
3 & 0,07 & 15,14 & 82,72 & 2,12 \\
4 & 0,08 & 12,09 & 85,72 & 2,18 \\
5 & 0,08 & 10,77 & 87,04 & 2,18 \\
8 & 0,09 & 10,44 & 87,35 & 2,19 \\
10 & 0,09 & 10,89 & 86,86 & 2,24 \\
\hline
\end{tabular}

PP - preço produtor; PA - preço atacado; PV - preço varejo.

Fonte: Dados da pesquisa.

Tabela A3 - Decomposição da variância dos erros de previsão do preço do suíno no atacado. São Paulo, 1995-2006. \%

\begin{tabular}{ccccc}
\hline Meses & Desvio-padrão & PP & PA & PV \\
\hline 1 & 0,05 & 0,00 & 100 & 0,00 \\
2 & 0,08 & 1,02 & 97,20 & 1,76 \\
3 & 0,10 & 2,33 & 95,58 & 2,07 \\
4 & 0,11 & 3,83 & 93,76 & 2,39 \\
5 & 0,12 & 5,31 & 92,04 & 2,64 \\
8 & 0,12 & 8,70 & 87,91 & 3,37 \\
10 & 0,13 & 9,90 & 86,19 & 3,89 \\
\hline
\end{tabular}

PP - preço produtor; PA - preço atacado; PV - preço varejo

Fonte: Dados da pesquisa. 
Tabela A4 - Decomposição da variância dos erros de previsão do preço do suíno no atacado. São Paulo, 1995-2006. \%

\begin{tabular}{ccccc}
\hline Meses & Desvio-padrão & PP & PA & PV \\
\hline 1 & 0,04 & 0,42 & 2,12 & 97,36 \\
2 & 0,05 & 0,62 & 12,74 & 86,63 \\
3 & 0,06 & 1,18 & 19,44 & 79,37 \\
4 & 0,07 & 1,86 & 24,72 & 73,4 \\
5 & 0,08 & 2,64 & 28,23 & 69,11 \\
8 & 0,10 & 5,04 & 33,22 & 61,73 \\
10 & 0,11 & 6,45 & 34,17 & 59,36 \\
\hline
\end{tabular}

PP - preço produtor; PA - preço atacado; PV - preço varejo.

Fonte: Dados da pesquisa.

Tabela A5 - Teste ARCH*

\begin{tabular}{lcc}
\hline Variável dependente (equação) & $\mathrm{p}$ & $\mathrm{TR}^{2}$ \\
\hline$h_{p p}$ (equação 4) & 12 & $\mathrm{TR}^{2}=128 \times 0,114=14,59$ \\
$h_{a p}$ (equação 5) & 3 & $\mathrm{TR}^{2}=128 \times 0,089=11,39$ \\
$h_{v p}$ (equação 6) & 11 & $\mathrm{TR}^{2}=128 \times 0,118=15,10$ \\
\hline
\end{tabular}

*Este teste é dado por $\mathrm{TR}^{2}$, em que T é o número de observações e $\mathrm{R}^{2}$ o coeficiente de ajustamento na equação da média do modelo, e tem distribuição $\chi^{2} \operatorname{com} \mathrm{p}$ graus de liberdade.

Tabela A6 - Modelo VAR de causalidade de Granger para os preços na cadeia suína

\begin{tabular}{lc}
\hline Sentido da causalidade dos preços & Significância da estatística qui-quadrado \\
\hline Produtor para atacado & $17 \%$ \\
Produtor para varejo & $9 \%$ \\
Atacado para produtor & $1 \%$ \\
Atacado para varejo & $3 \%$ \\
Varejo para produtor & $2 \%$ \\
Varejo para atacado & $8 \%$ \\
\hline
\end{tabular}

Fonte: Dados da pesquisa. 
REVISTA DE ECONOMIA E AGRONEGÓCIO, VOL.4, $N^{o} 3$ 